\title{
Trends and correlates of cesarean section rates over two decades in Nepal
}

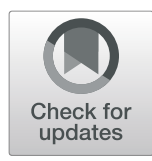

\author{
Aliza K. C. Bhandari (D, Bibha Dhungel and Mahbubur Rahman
}

\begin{abstract}
Background: Cesarean section (CS) is a major component of emergency obstetric care. There has been a substantial rise in the rate of CS in private institutions in Nepal which might reflect the successful implementation of delivery schemes introduced by the government extended to the private organizations alternatively, it may also reflect the need for more public health care facilities to provide maternal and child health care services. Hence, the objective of this study was to examine the trends in institutional-based CS rates in Nepal along with its correlates over time.

Methods: We used the National Demographic and Health Survey (NDHS) data collected every 5 years, from 1996 to 2016. The trend in CS rates based on five waves of NDHS data along with its correlates were examined using multivariable logistic regression models after adjusting for socio-demographics and pregnancy-related variables.

Results: We included 20,824 reproductive-aged women who had a history of delivery within the past 5 years. The population-based CS rate increased from 0.9\% in 1996 [95\% Cl: (0.6-1.2) \%] to 10.2\% in 2016 [95\% Cl: (8.9-11.6) \%, $p<0.01]$ whereas the institutional-based CS rate increased from 10.4\% in 1996 [95\% Cl: (8.3-12.9) \%] to $16.4 \%$ in 2016 [95\% Cl: (14.5-18.5) \%, $p<0.01]$. Private institutions had a nearly 3-fold increase in CS rate (8.9\% in 1996 [95\% Cl: (4.8-16.0) \%] vs. $26.3 \%$ in $2016[95 \%$ Cl: (21.9-31.3) \%]. This was also evident in the trend analysis where the odds of having CS was 3.58 times higher [95\% Cl: (1.83-7.00), p < 0.01] in 2016 than in 1996 in the private sectors, while there was no evidence of an increase in public hospitals (10.9\% in 1996 to 12.9\% in 2016; $p$ for trend $>0.05$ ). Education of women, residence, wealth index, parity and place of delivery were significantly associated with the CS rate.

Conclusion: Nepal has observed a substantial increase in cesarean delivery over the 20 years, which might indicate a successful implementation of the safe motherhood program in addressing the Millennium Development Goals and Universal Health Care agenda on maternal and child health. However, the Nepal government should examine existing disparities in accessibility of emergency obstetric care services, such as differences in CS between public and private sectors, and promote equity in maternal and child health care services accessibility and utilization.
\end{abstract}

Keywords: Cesarean section, Trends, Correlates, Nepal, Operative delivery

\footnotetext{
* Correspondence: 18mp204@slcn.ac.jp

St. Luke's International University Graduate School of Public Health, Tokyo,

Japan
}

(c) The Author(s). 2020 Open Access This article is licensed under a Creative Commons Attribution 4.0 International License, which permits use, sharing, adaptation, distribution and reproduction in any medium or format, as long as you give appropriate credit to the original author(s) and the source, provide a link to the Creative Commons licence, and indicate if changes were made. The images or other third party material in this article are included in the article's Creative Commons licence, unless indicated otherwise in a credit line to the material. If material is not included in the article's Creative Commons licence and your intended use is not permitted by statutory regulation or exceeds the permitted use, you will need to obtain permission directly from the copyright holder. To view a copy of this licence, visit http://creativecommons.org/licenses/by/4.0/. The Creative Commons Public Domain Dedication waiver (http://creativecommons.org/publicdomain/zero/1.0/) applies to the data made available in this article, unless otherwise stated in a credit line to the data. 


\section{Background}

Cesarean section (CS) is a major component of emergency obstetric care performed to reduce maternal and fetal morbidity and mortality [1]. However, some studies have shown the increased risks associated with cesarean section compared with normal vaginal delivery for both mother and her child, especially if the CS is not medically indicated [2]. According to World Health Organization's (WHO) estimates, about 6.2 million unnecessary $\mathrm{CS}$ are being performed annually in the world [3]. WHO recommends the national cesarean section (CS) rate to be between 10 and $15 \%$ with $<10$ and $>15 \%$ representing underuse and overuse of maternal and child health care services, respectively [3]. In 2015, WHO added that, population-based CS rates of more than $10 \%$ are not associated with a reduction in maternal and neonatal mortality rates; however, they did not include the association between stillbirths or maternal and perinatal morbidity and CS rates due to unavailability of data [4]. Furthermore, a cross-sectional ecological study conducted among all 194 WHO member states concluded that the population-level CS rates of up to approximately 19 per 100 live births were associated with lower maternal and neonatal mortality [5]. Thus, it is still not clear to what extent of CS rate is considered safe.

Despite this, there is an alarming increase in the CS rate worldwide, with a wide disparity between low and high-income countries [6]. In a recent study, which included data from 169 countries across the globe in 2015, the overall CS rate was reported to be $21.1 \%$, twice as high as that estimated based on 2000 data [7]. A rate of more than 40\% was observed in the Latin America and the Caribbean, followed by Northern America (32.3\%), Oceania (31.1\%), Europe (25\%), Asia (20\%) and Africa (7.3\%) [7]. Another study based on the WHO Global Survey on Maternal and Perinatal Health conducted in 2007-2008 among nine Asian countries, observed the national CS rates between 14.7 and $46.2 \%$ [8]. With the rapid rise in the CS rate, there have been concerns over the growing disparity of obstetric care service access and utilization. The inequitable distribution of health care resources in certain regions with limited health care facilities has left millions of people without adequate access to such services and expose them to the hazards of unsafe delivery [8].

The determinants of CS are varied and complex [9]. Several studies indicated that the rise in CS rate may be associated with the socio-demographic influences [10], and natal and antenatal factors such as maternal age, socio-economic index (education, wealth index, occupation) [11], place of residence [12], maternal body mass index (BMI) [13], birth order and birth weight of the child [14], previous experience with CS [15], obstetric complications [16], maternal preference [17] and place of delivery [18]. The influence of these factors varied among different populations [19].

Nepal expanded the emergency obstetric care services by promoting Skilled Birth Attendant (SBA) training programs in almost all districts of the country, which was implemented successfully to meet the Millennium Development Goals (MDG) target of reducing the maternal mortality rate by three-quarters to 134 per 100 , 000 live births by 2015. In addition to SBA training, the safe delivery incentive program was introduced by the Nepal Government in 2005 to promote the institutionalbased deliveries. This program provided a cash incentive of Nepalese rupee (NPR) 500, NPR1000, NPR1500 (1 United States Dollar $=$ NPR118.7) for the residence of Terai, Hills and Himalayan regions respectively, to women who delivered their baby in an institution. The incentive was also provided to the service providers based on the number of deliveries attended in a health facility or even for home deliveries [20]. In 2009, with the introduction of the Aama Suraksha Program, the out-of-pocket payments associated with institutionalbased deliveries in all government health care facilities as well as in some private medical college hospital facilities were abolished [21]. Similarly, women were provided with an additional incentive of NPR400 for completing four antenatal checkup visits and first postnatal checkup visit in addition to the institutional delivery since 2009/2010. All these factors may have played important roles in reducing maternal and child health mortality rates by increasing CS services [22, 23]. However, most of these programs focused on the Basic Emergency Obstetric Care (BEmOC) Services only and incorporating the Comprehensive Emergency Obstetric Care (CEmOC) services in the hospitals was much slower indicated by the fact that more than a third of districts did not have CS capabilities in the public sector prior to 2010.

A study reported that the increase in CS rate in Nepal might be partly driven by the private sectors [24]. Large disparity in CS utilization in the urban and rural areas has also been reported [25]. Some socio-demographic factors such as age, education, economic stability and having an educated partner are associated with population-based CS rates [26, 27]. In a developing country like Nepal, where resources are not distributed evenly at hospitals and health facilities, analysis of the entire population does not give a clear picture of existing disparities in health care utilization. The rates of cesarean section in the health care facilities depend on the number of people they serve and clearly, the flow of patients in private facilities is more compared to government health care facilities [4]. Therefore, it would be inappropriate to apply the population-based cesarean rates at facility level as difference might exist in between 
private and government facilities. Many studies lacked a comparative trend analysis considering these differences between private and public sectors with regard to the determinants leading to increase in the CS rates. Similarly, the effects of various socio-demographic and natal and antenatal factors of women on the CS rate remain unexplored despite the fact that understanding these correlates might shed more light on existing disparities within the country. Also, in light of the significant rise in CS rates both globally and in Nepal there is a need to track whether this progress is inequitable or not. Thus, the objective of this study is to examine the trends in institutional-based CS in Nepal over two decades along with its correlates over time in Nepal.

\section{Methods}

\section{Study design}

For this study, the National Demographic and Health Survey (NDHS) data collected in Nepal in the years 1996, 2001, 2006, 2011 and 2016 were used with the permission obtained from the Demographic and Health Survey program department, USAID [28]. The NDHS collected data based on nationally representative samples by multi-stage cluster sampling design every 5 years in Nepal similar to that of many other developing countries using census ward as a primary sampling unit.

\section{Study participants}

Overall, data on pregnancy and childbirth history was collected from 53,484 women aged 15 to 49 years that yielded an average response rate of $98.2 \%$. This study only included women who responded to the NDHS question on whether their last birth in the last 5 years was through CS delivery. Women who had missing or erroneous records for the outcome of interest (cesarean section) were excluded from the analysis. In total, 20,824 women had a history of delivery in the last 5 years and information on whether CS was performed (3827 in 1996, 4730 in 2001, 4182 in 2006, 4079 in 2011 and 4006 in 2016).

\section{Outcome of interest}

The main outcome of interest was cesarean section delivery which was measured in the National Demographic and Health Survey using a binary response "Yes" or "No". Institutional-based CS rate is defined as the operative delivery performed in private or public health care facilities per 100 live births.

\section{Independent variables}

\section{Socio-demographics}

This study included the following independent variables: women's age, religion, education (less than or equal to primary education which is up to 5th grade of schooling versus more than or equal to secondary which is above 5th grade of schooling), residence, region (five developmental regions)/ province (seven provinces), age at first marriage and age at first birth, occupation, BMI, wealth index (divided into five equal quintiles from poorest to richest). In the NDHS, households are given scores based on the number and kinds of consumer goods they own, ranging from a television to a bicycle or car, and housing characteristics such as source of drinking water, toilet facilities, and flooring materials. These scores are derived using principal components analysis. National wealth quintiles are compiled by assigning the household score to each usual household member, ranking each person in the household population by her/his score, and then dividing the distribution into 12 . Housing characteristics and household population have five equal categories, each comprising $20 \%$ of the population. Husband's education was classified in a similar way as the women's education. Provincial system was introduced in Nepal after 2015; thus, analysis based on 2016 data only included this variable. In 2015, one district was divided into two and two other districts were merged together to form a single district in Nepal. Hence, a separate analysis which included province as a covariate is shown in "Additional file 1".

\section{Natal and antenatal factors}

We also included variables such as place of institutional delivery as "Government sector versus Non-Government sector", number of antenatal care visits and size of the infant at birth in the analysis.

\section{Statistical analysis}

We conducted univariate analysis and presented a weighted frequency. Bivariable analysis was conducted using the chi-square test or Fisher's exact test as appropriate. Furthermore, bivariable logistic regression was performed and those covariates which were significant in the bivariable model at $p<0.05$ were kept in the multivariable logistic regression model. Trend analysis was performed using logistic regression analysis after combining all the data across survey waves.

We conducted separate multivariable logistic regression models for each of the five waves of data. We excluded variables showing high collinearity, such as age at first marriage and husbands' education, from all the regression models. Women's BMI was also excluded due to high number of missing values across different waves of data. We also performed multivariable logistic regression analysis stratified by place of delivery (government versus private). We used $p<0.05$ to indicate statistical significance in the bivariable and multivariable models. Weight variables included in the DHS databases considered the clustered nature of the data as well as other 
complex survey design issues. We used sample weight variable and conducted all the statistical analyses using "svy" command to account for clustering of the survey data.

Because of the very low number of events based on institutional births in the year 1996 and 2001, we did not report logistic regression analysis for these two survey waves and included them in "additional file 1" instead. Similarly, to examine the association with province variable (available only for the 2016 survey wave data), we fitted separate logistic regression model ("Additional file 1"). Stata IC version 15.1 was used for data coding and analysis.

\section{Ethical consideration}

This study analyzed data extracted from the NDHS 1996, 2001, 2006, 2011 and 2016 surveys. The ethical clearance for these surveys was obtained from Nepal Research Council and ICF Macro Institutional Review Board in Calverton, Maryland, USA. The DHS data are publicly accessible while we obtained the permission to use it in May 2019 after DHS reviewed our proposal and we accepted the terms and conditions attached with data sharing policy [28].

\section{Results}

In total, 20,824 women aged $15-49$ years had a history of childbirth within the last 5 years of interview and information on whether they had CS delivery. Sociodemographic characteristics of the women based on five waves of survey data are shown in Table 1 (all birth versus institutional birth). Of total participants, the majority of women were aged between 20 and 29 years and identified their religion as Hindu.

Overall, the frequency of women with secondary education or above increased from $9.4 \%$ in 1996 to nearly $50 \%$ in 2016 . The level of education was higher throughout the survey waves among women who had an institutional birth. Until 2011, the majority of women were residing in rural areas. However, in 2016, two-thirds of the women who gave birth in an institution were from urban residences (64.9\%). About $60 \%$ of women who had an institutional delivery were employed, and more than $70 \%$ belonged to average or higher wealth quintiles in 2016, and almost 51\% had their first child at the age of $\leq 19$. The majority of women had normal BMI, and education level of their husband increased over time.

Until 2016, the majority of births took place at home, with just $0.9 \%$ of births occurring in a facility in 1996; this increased to $18 \%$ in 2006 and $62 \%$ in 2016. Most of the respondents were multiparous $(78.3 \%$ in 1996 and $62.5 \%$ in 2016). However, there was a significant shift in primiparous women from $22 \%$ in 1996 to $37.5 \%$ in 2016 . Majority of women had an average-sized infant throughout the survey years (nearly 43\% in 1996 to $65.8 \%$ in 2016). The rate of complete four antenatal care visits or more, as recommended by WHO, increased about 8 -fold from 1996 to 2016 with a higher rate among women who had institutional deliveries. Eastern, Central and Western developmental regions together comprised of more than $70 \%$ of the study participants in all survey waves. Similarly, with the addition of the provincial system in 2016, province 2 had the highest number of participants (24.1\%).

The population-based CS rate had increased 10-fold, from $0.9 \%$ in 1996 [95\% CI: $(0.6-1.2) \%$ ] to $10.2 \%$ in 2016 [95\% CI: $(8.9-11.6) \%, p<0.01]$ whereas the institutional-based CS rate increased from 10.4\% in 1996 [95\% CI: $(8.3-12.9) \%$ ] to $16.4 \%$ in 2016 [95\% CI: (14.518.5) $\%, p<0.01$ ]. Private institutions had a nearly 3 -fold increase in CS rate (8.9\% in 1996 [95\% CI: (4.8-16.0) \%] vs. $26.3 \%$ in 2016 [95\% CI: (21.9-31.3) \%]. This was also evident in the trend analysis where the odds of having CS was almost 4-fold higher [OR: 3.58, 95 95\% CI: (1.83-7.00), $p<0.01]$ in 2016 than in 1996 in the private sectors while there was no evidence of an increase in public hospitals (10.9\% in 1996 to $12.9 \%$ in 2016; $p$ for trend $>0.05$ ). (Fig. 1 and Table 2).

Caesarean section rates varied across most sociodemographic and pregnancy-related variables, at each time point/survey (Table 3). Multivariable logistic regression analyses showed that women who had their baby after 30 years of age were nearly five times more likely to have CS in all of the survey waves than the women who had early childbirth and this association was highly significant in 2011 and 2016 survey waves than in 2006. Women had higher likelihood of CS for their first child in 2006, but similar results were not observed in recent survey years. With the increase in wealth index, the likelihood of having a cesarean section increased nearly 4-fold in 2016. However, it was not statistically significant in other survey waves. Women who delivered larger sized infants had a higher likelihood of getting CS than their counterparts almost in all survey waves (Table 4).

All regions had a higher CS rate than the far western development region in all survey waves. In 2016, women residing in the Eastern, Western and Central regions had two- to three-fold likelihood of having CS than women residing in the far western region. In addition, women in urban areas had a nearly two-fold likelihood of getting CS than those residing in the rural areas based on 2011 survey data only. The likelihood of getting CS was more than two-fold higher in private sectors than in government sectors in the last two survey rounds. Separate multivariable logistic regression analysis stratified by the place of delivery showed, by and large, similar correlates (Table 5). In comparison with the other five 
Table 1 Socio-demographic characteristics of all women of reproductive age grouped by survey waves

\begin{tabular}{|c|c|c|c|c|c|c|c|c|c|c|}
\hline & $\begin{array}{l}\text { NDHS- } \\
1996\end{array}$ & $\begin{array}{l}\text { Inst. births } \\
N=334 \%\end{array}$ & $\begin{array}{l}\text { NDHS- } \\
2001\end{array}$ & $\begin{array}{l}\text { Inst. births } \\
N=235 \%\end{array}$ & $\begin{array}{l}\text { NDHS- } \\
2006\end{array}$ & $\begin{array}{l}\text { Inst. births } \\
N=854 \%\end{array}$ & $\begin{array}{l}\text { NDHS- } \\
2011\end{array}$ & $\begin{array}{l}\text { Inst. births } \\
N=1682 \%\end{array}$ & $\begin{array}{l}\text { NDHS- } \\
2016\end{array}$ & $\begin{array}{l}\text { Inst. births } \\
N=2485 \%\end{array}$ \\
\hline & $\begin{array}{l}\text { All births } \\
N=3821 \%\end{array}$ & & $\begin{array}{l}\text { All births } \\
N=4693 \%\end{array}$ & & $\begin{array}{l}\text { All births } \\
N=4182 \%\end{array}$ & & $\begin{array}{l}\text { All births } \\
N=4079 \%\end{array}$ & & $\begin{array}{l}\text { All births } \\
N=4006 \%\end{array}$ & \\
\hline \multicolumn{11}{|l|}{ Age of women } \\
\hline$\leq 19$ & 10.6 & 10.9 & 8.0 & 10.5 & 8.0 & 11.5 & 8.0 & 11.1 & 8.4 & 9.8 \\
\hline $20-29$ & 58.7 & 71.7 & 57.4 & 61.4 & 63.6 & 65.9 & 36.6 & 67.6 & 66.3 & 68.0 \\
\hline $30+$ & 30.7 & 17.4 & 34.6 & 28.1 & 28.4 & 22.6 & 28.4 & 21.3 & 25.3 & 22.2 \\
\hline \multicolumn{11}{|l|}{ Religion } \\
\hline Hindu & 85.9 & 88.0 & 84.1 & 88.4 & 84.9 & 85.1 & 83.0 & 86.0 & 85.6 & 86.0 \\
\hline Others & 14.1 & 12.0 & 15.9 & 11.6 & 15.1 & 14.9 & 17.0 & 14.0 & 14.4 & 14.0 \\
\hline \multicolumn{11}{|l|}{ Education } \\
\hline $\begin{array}{l}\text { No } \\
\text { education }\end{array}$ & 79.2 & 41.8 & 72.7 & 48.8 & 57.9 & 28.1 & 43.9 & 24.2 & 31.5 & 20.3 \\
\hline$\leq$ Primary & 11.4 & 16.3 & 14.3 & 12.4 & 18.3 & 17.9 & 20.1 & 18.2 & 19.4 & 16.8 \\
\hline$\geq$ Secondary & 9.4 & 41.9 & 12.9 & 38.8 & 23.8 & 54.0 & 36.0 & 57.6 & 49.1 & 62.9 \\
\hline \multicolumn{11}{|l|}{ Residence } \\
\hline Rural & 93.5 & 64.4 & 93.2 & 83.9 & 86.8 & 66.9 & 89.9 & 81.1 & 44.4 & 35.1 \\
\hline Urban & 6.5 & 35.6 & 6.8 & 16.1 & 13.2 & 33.1 & 10.1 & 18.9 & 55.6 & 64.9 \\
\hline \multicolumn{11}{|l|}{ Cesarean section } \\
\hline No & 99.1 & 89.6 & 99.6 & 92.4 & 96.7 & 84.3 & 94.8 & 87.0 & 89.8 & 83.6 \\
\hline Yes & 0.9 & 10.4 & 0.4 & 7.6 & 3.3 & 15.7 & 5.2 & 13.0 & 10.2 & 16.4 \\
\hline \multicolumn{11}{|c|}{ Age at first marriage } \\
\hline$\leq 19$ & 88.5 & 74.1 & 87.7 & 77.5 & 83.7 & 68.3 & 77.7 & 68.0 & 74.2 & 67.8 \\
\hline $20-29$ & 11.3 & 25.0 & 12.2 & 22.5 & 16.0 & 31.3 & 21.9 & 31.6 & 25.0 & 31.0 \\
\hline $30+$ & 0.2 & 0.9 & 0.1 & 0 & 0.3 & 0.4 & 0.4 & 0.4 & 0.8 & 1.2 \\
\hline \multicolumn{11}{|l|}{ Age at first birth } \\
\hline$\leq 19$ & 61.7 & 46.4 & 60.3 & 51.5 & 58.2 & 45.6 & 52.8 & 43.9 & 50.7 & 44.9 \\
\hline $20-29$ & 37.5 & 50.2 & 39.0 & 47.3 & 40.6 & 51.7 & 46.0 & 54.4 & 48.0 & 53.3 \\
\hline $30+$ & 0.8 & 3.4 & 0.7 & 1.2 & 1.2 & 2.7 & 1.2 & 1.7 & 1.3 & 1.8 \\
\hline \multicolumn{11}{|l|}{ Occupation } \\
\hline Not working & 16.9 & 41.4 & 16.2 & 26.1 & 19.4 & 36.2 & 27.7 & 40.2 & 38.7 & 41.8 \\
\hline Working & 83.1 & 58.6 & 83.8 & 73.9 & 80.6 & 63.8 & 72.3 & 59.8 & 61.3 & 58.2 \\
\hline \multicolumn{11}{|l|}{ Wealth index } \\
\hline Poorest & 14.3 & 22.1 & 15.3 & 18.2 & 23.5 & 8.4 & 23.6 & 8.9 & 20.5 & 13.0 \\
\hline Poorer & 20.4 & 25.7 & 18.5 & 17.9 & 21.1 & 10.4 & 21.7 & 14.8 & 21.0 & 17.3 \\
\hline Middle & 19.2 & 17.3 & 15.8 & 21.0 & 20.0 & 12.3 & 21.0 & 19.9 & 21.6 & 21.7 \\
\hline Richer & 18.9 & 18.6 & 22.7 & 19.9 & 18.5 & 22.0 & 18.0 & 24.8 & 20.8 & 24.2 \\
\hline Richest & 27.1 & 16.3 & 27.8 & 23.0 & 16.9 & 46.9 & 15.7 & 31.6 & 16.1 & 23.8 \\
\hline \multicolumn{11}{|c|}{ Husband's education } \\
\hline $\begin{array}{l}\text { No } \\
\text { education }\end{array}$ & 38.8 & 13.3 & 34.9 & 20.3 & 23.5 & 12.0 & 21.0 & 10.8 & 13.5 & 8.2 \\
\hline$\leq$ Primary & 23.9 & 15.6 & 24.7 & 18.7 & 28.8 & 20.2 & 23.7 & 17.1 & 21.2 & 16.7 \\
\hline$\geq$ Secondary & 37.2 & 70.7 & 38.1 & 58.6 & 47.2 & 67.7 & 54.8 & 71.9 & 64.3 & 74.1 \\
\hline Missing & 0.2 & 0.3 & 2.3 & 2.4 & 0.5 & 0.1 & 0.5 & 0.2 & 1.0 & 1.0 \\
\hline \multicolumn{11}{|l|}{ Body mass index } \\
\hline High risk & 27.5 & 25.3 & 28.6 & 27.4 & 30.6 & 33.1 & 14.8 & 16.2 & 18.1 & 19.0 \\
\hline
\end{tabular}


Table 1 Socio-demographic characteristics of all women of reproductive age grouped by survey waves (Continued)

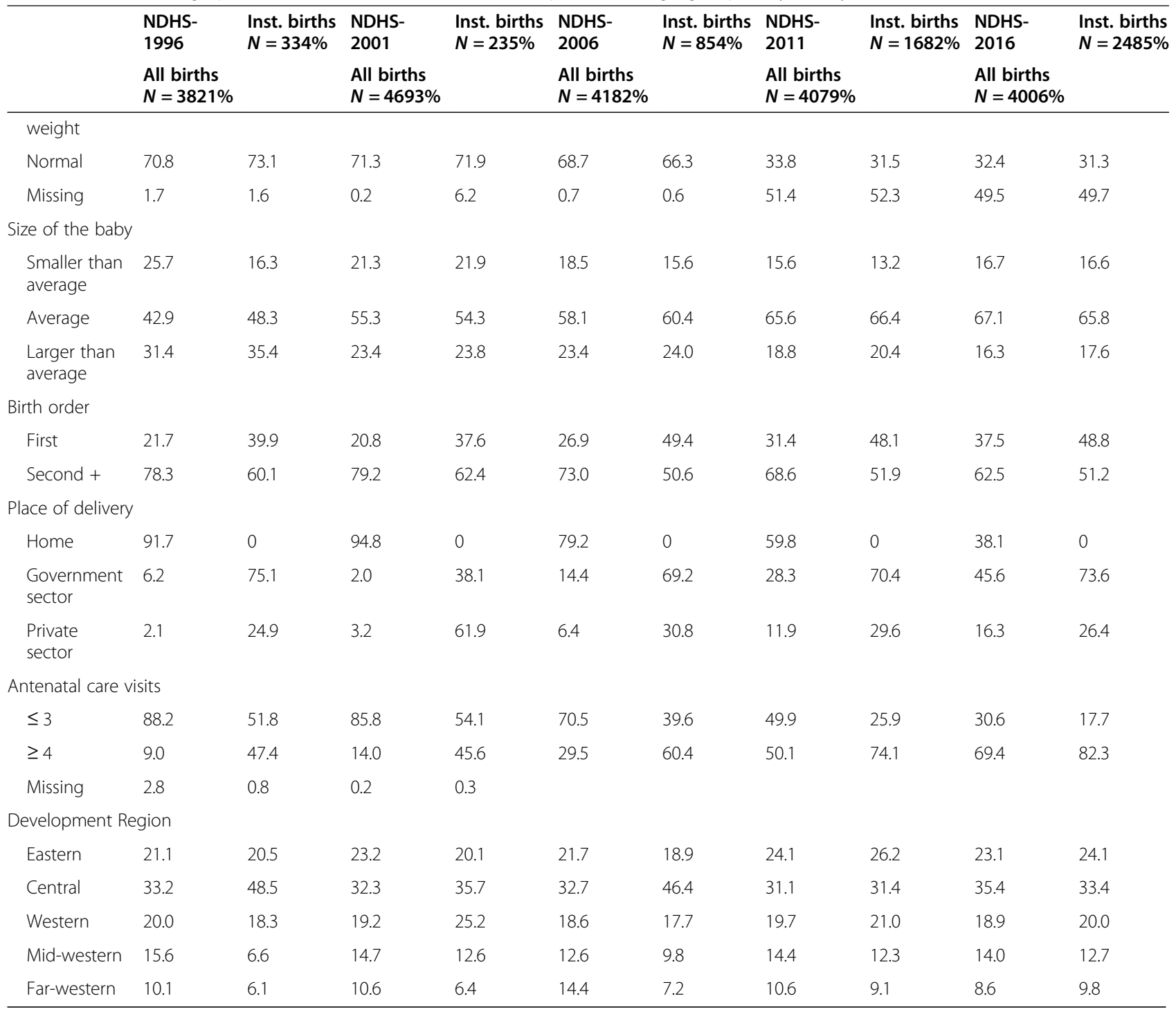

NDHS National Demographic and Health Survey, Inst. Births Institutional-based deliveries

All births are total births, including home delivery and institutional deliveries in the respective survey rounds, whereas institutional births are the total number of births in an institution in the respective survey waves

provinces, province three and four had nearly 2.5 times higher risk of having CS (Additional file 1).

\section{Discussion}

This study highlighted the trends in institutional-based CS among Nepalese women over the past two decades using five survey waves (1996, 2001, 2006, 2011 and 2016) and also identified maternal socio-demographic and pregnancy-related factors associated with this trend.

Nepal observed a 6-percentage point rise in the institutional-based CS rate in 2016 compared to 1996 (10.4\% versus $16.4 \%)$. However, the population-based CS rates have not exceeded the upper limit based on WHO guidelines [4]. This sharp increase in the rate of institutional-based CS rates in Nepal may have reflected the improved maternal and child health care access throughout the country. Compared to 1996 data, Nepal was able to significantly reduce maternal mortality rate (MMR) related to obstetric complications to meet the MDG 2015 of 50\% MMR reduction using a very concrete National action plan and SBA training programs [29]. Similar escalating trend in the CS rates has been observed in other countries of the world. Western countries such as Germany, Italy, Denmark and Australia had CS rates over $10 \%$ during the 1990 s, which increased 24 fold a couple of decades later [30]. Similarly, some of the developing countries in Asia also showed an upward trend. For example, CS rate increased to $24.5 \%$ in 2011 from 14.3\% in 2007 in Bangladesh [10, 14]. India also showed a similar trend like that of Nepal with an 


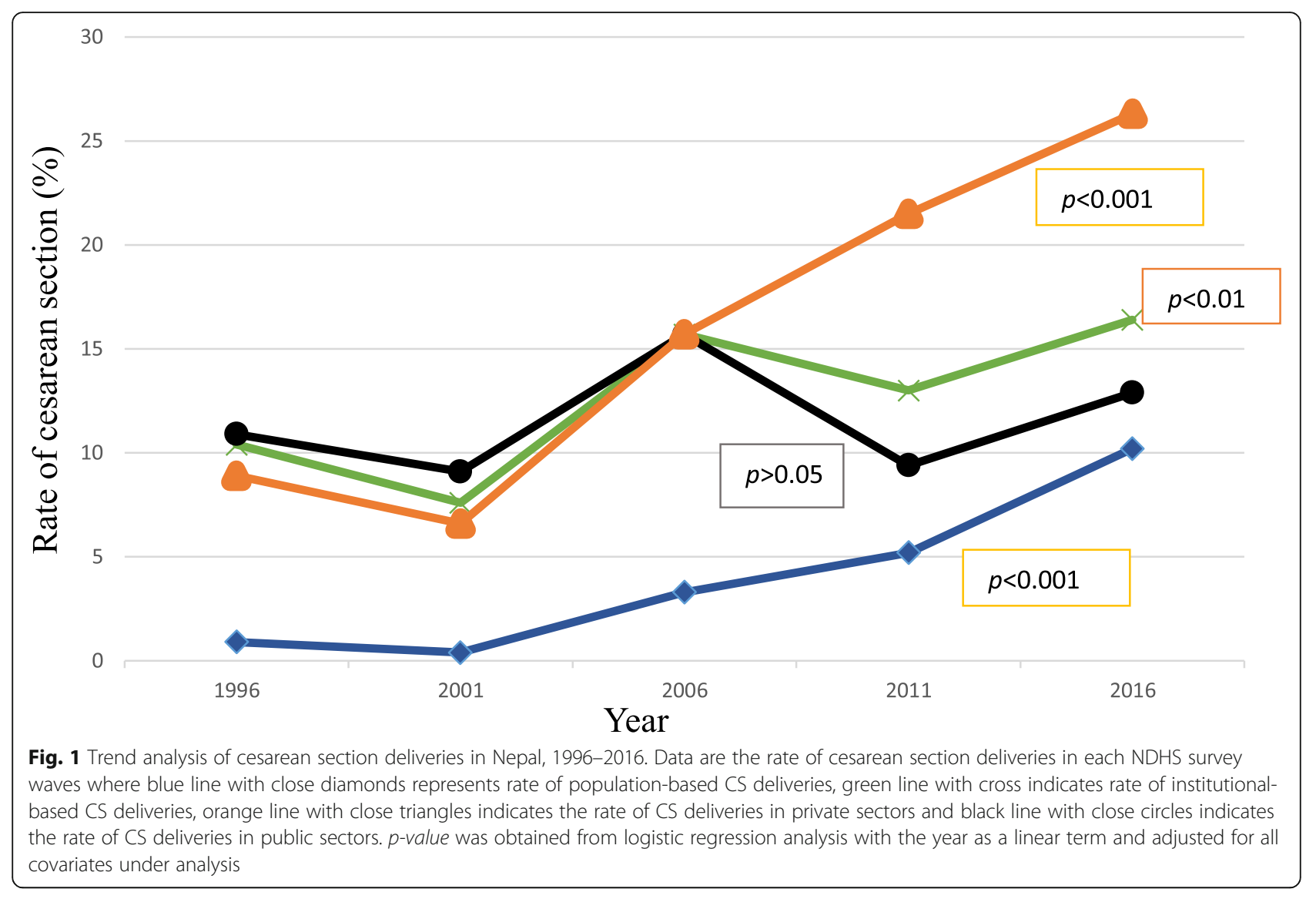

institutional-based CS rate of $21.8 \%$ in 2016 compared to $11 \%$ reported in 1988 [31]. Several factors such as maternal education, wealth index, and accessibility to emergency obstetric care, women's preferences and healthrelated policy factors of the country may be responsible for an upward trend in CS rates in these countries [32]. The increasing rate of CS is an important indicator of advancing health care services, especially for low-income countries like Nepal.
Several factors were identified as correlates of CS rate in this study. Nepal has shown a drastic change in the distribution of women by residence. A recent study reported that women living in rural areas have no or less access to emergency obstetric care [33, 34]. The lower CS rate in rural areas compared to that of urban areas might be associated with several existing barriers to maternal and child health care in rural areas. Also, women with higher socio-economic status [35], higher maternal

Table 2 Trend of institutional-based cesarean section stratified by the place of delivery based on bivariable and multivariable logistic regression analysis

\begin{tabular}{|c|c|c|c|c|}
\hline & \multicolumn{2}{|l|}{ Public sector } & \multicolumn{2}{|l|}{ Private sector } \\
\hline & cOR (Cl) & aOR (Cl) & cOR (Cl) & aOR (Cl) \\
\hline \multicolumn{5}{|l|}{ Year } \\
\hline 1996 & 1 & 1 & 1 & 1 \\
\hline 2001 & $0.82(0.48-1.40)$ & $0.87(0.50-1.51)$ & $0.71(0.36-1.42)$ & $0.93(0.47-1.83)$ \\
\hline 2006 & $1.53(0.95-2.45)$ & $1.11(0.71-1.75)$ & $1.89(0.93-3.86)$ & $1.94(0.95-3.94)$ \\
\hline 2011 & $0.85(0.56-1.28)$ & $0.84(0.54-1.29)$ & $2.78(1.43-5.39) * *$ & $2.56(1.31-4.98) * *$ \\
\hline 2016 & $1.21(0.84-1.74)$ & $1.22(0.82-1.80)$ & $3.63(1.85-7.11) * * *$ & $3.58(1.83-7.00) * * *$ \\
\hline
\end{tabular}

Number of cases included in the multivariable model $N=5090$

COR crude odds ratio obtained from bivariable analysis

$a O R$ adjusted odds ratio (adjusted for all covariates under analysis for each survey wave)

Cl 95\% confidence interval

${ }^{* *}=P<0.01,{ }^{* * *}=P<0.001$ 
Table 3 Proportion of institutional-based cesarean section and its association with selected covariates in respective survey waves

\begin{tabular}{|c|c|c|c|c|c|}
\hline & \multicolumn{5}{|c|}{ Cesarean section (weighted \%) } \\
\hline & $1996 N=334$ & $2001 N=235$ & $2006 N=854$ & $2011 N=1682$ & $2016 N=2485$ \\
\hline \multicolumn{6}{|l|}{ Age of women } \\
\hline$\leq 19$ & $4(13.0)$ & $1(5.9)$ & $14(16.0)$ & $10(6.0)$ & $24(9.5)$ \\
\hline $20-29$ & $25(10.1)$ & $12(4.4)$ & $71(16.1)$ & $143(12.3)$ & $243(15.8)$ \\
\hline$\geq 30$ & $5(10.1)$ & $6(8.5)$ & $26(14.4)$ & 61 (18.6) & $99(21.4)$ \\
\hline$p$-value & 0.729 & 0.766 & 0.896 & $<0.01$ & $<0.01$ \\
\hline \multicolumn{6}{|l|}{ Religion } \\
\hline Hindus & $31(11.1)$ & $16(7.2)$ & $97(14.9)$ & $189(13.2)$ & $311(16.2)$ \\
\hline Non-Hindus & $3(5.9)$ & $3(10.2)$ & $14(20.1)$ & $25(11.8)$ & $55(17.6)$ \\
\hline$p$-value & 0.189 & $<0.05$ & 0.489 & 0.697 & 0.642 \\
\hline \multicolumn{6}{|l|}{ Education } \\
\hline No education & $15(13.1)$ & $9(7.8)$ & $21(13.8)$ & $28(8.8)$ & $52(12.1)$ \\
\hline Primary or less & $4(5.9)$ & $1(2.7)$ & $20(16.2)$ & 35 (13.3) & 46 (11.3) \\
\hline Secondary + & $15(9.4)$ & $9(8.8)$ & 70 (16.5) & 151 (14.6) & $268(19.2)$ \\
\hline$p$-value & 0.050 & 0.307 & 0.750 & 0.069 & $<0.001$ \\
\hline \multicolumn{6}{|l|}{ Residence } \\
\hline Rural & $18(9.6)$ & $8(4.5)$ & $56(14.0)$ & $100(10.9)$ & $106(13.7)$ \\
\hline Urban & 16 (11.8) & $11(23.7)$ & $55(19.1)$ & $114(22.0)$ & $260(17.9)$ \\
\hline$p$-value & 0.391 & $<0.001$ & 0.148 & $<0.001$ & $<0.05$ \\
\hline \multicolumn{6}{|l|}{ Age at first birth } \\
\hline$\leq 19$ & $13(8.8)$ & $5(4.1)$ & $38(11.0)$ & $64(8.7)$ & 119 (10.7) \\
\hline $20-29$ & $17(9.8)$ & $13(10.2)$ & 65 (18.4) & 139 (15.7) & $228(20.2)$ \\
\hline$\geq 30$ & $4(42.6)$ & $1(53.6)$ & $8(42.8)$ & $11(35.8)$ & $19(45.2)$ \\
\hline$p$-value & $<0.01$ & $<0.001$ & $<0.01$ & $<0.001$ & $<0.001$ \\
\hline \multicolumn{6}{|l|}{ Birth order } \\
\hline Second + & $13(7.1)$ & $9(5.2)$ & $39(10.5)$ & $107(12.2)$ & $164(14.2)$ \\
\hline First & $21(15.3)$ & $10(11.4)$ & $72(21.0)$ & $107(13.8)$ & $202(18.7)$ \\
\hline$p$-value & $<0.01$ & $<0.05$ & $<0.01$ & 0.382 & $<0.05$ \\
\hline \multicolumn{6}{|l|}{ Occupation } \\
\hline Not working & $15(8.7)$ & $7(10.0)$ & $60(24.0)$ & $102(16.5)$ & $164(18.4)$ \\
\hline Working & 19 (11.7) & $12(0.67)$ & $51(11.0)$ & 112 (10.6) & $202(14.9)$ \\
\hline$p$-value & 0.098 & 0.121 & $<0.001$ & $<0.01$ & 0.061 \\
\hline \multicolumn{6}{|l|}{ Wealth index } \\
\hline Poorest & $7(10.2)$ & $6(10.8)$ & $6(10.6)$ & $12(9.2)$ & $27(7.4)$ \\
\hline Poorer & $10(13.1)$ & $4(9.5)$ & $6(7.3)$ & $9(2.8)$ & $40(9.2)$ \\
\hline Middle & $4(6.3)$ & $3(4.2)$ & $8(9.3)$ & $34(13.6)$ & $63(12.6)$ \\
\hline Richer & $6(11.5)$ & $3(7.7)$ & $17(10.0)$ & $48(13.0)$ & $89(14.0)$ \\
\hline Richest & $7(9.5)$ & $3(6.4)$ & 74 (22.8) & $111(18.4)$ & 147 (32.4) \\
\hline$p$-value & 0.453 & 0.176 & $<0.001$ & $<0.001$ & $<0.001$ \\
\hline \multicolumn{6}{|l|}{ Size of the baby } \\
\hline Average & $12(17.0)$ & $10(6.1)$ & $56(11.7)$ & $136(11.8)$ & $224(15.0)$ \\
\hline Large & $19(6.9)$ & $4(6.8)$ & $35(23.2)$ & 49 (16.3) & $75(21.4)$ \\
\hline Small & $3(6.4)$ & $5(11.1)$ & 19 (18.9) & $28(12.9)$ & $67(16.8)$ \\
\hline$p$-value & $<0.001$ & 0.243 & $<0.05$ & 0.305 & $<0.05$ \\
\hline
\end{tabular}


Table 3 Proportion of institutional-based cesarean section and its association with selected covariates in respective survey waves (Continued)

\begin{tabular}{|c|c|c|c|c|c|}
\hline & \multicolumn{5}{|c|}{ Cesarean section (weighted \%) } \\
\hline & $1996 N=334$ & $2001 N=235$ & $2006 N=854$ & $2011 N=1682$ & $2016 N=2485$ \\
\hline \multicolumn{6}{|l|}{ Place of delivery } \\
\hline Government & $27(10.9)$ & $10(9.1)$ & $71(15.7)$ & $112(9.4)$ & $138(12.9)$ \\
\hline Private/others & $7(8.9)$ & $9(6.6)$ & $40(15.7)$ & $102(21.5)$ & $228(26.3)$ \\
\hline$p$-value & 0.558 & $<0.05$ & 0.992 & $<0.001$ & $<0.001$ \\
\hline \multicolumn{6}{|l|}{ ANC Visits } \\
\hline Less than 4 & $15(8.5)$ & $127(4.6)$ & $29(11.0)$ & $32(9.6)$ & $44(12.0)$ \\
\hline 4 or more & $19(12.7)$ & $107(10.4)$ & $82(18.8)$ & $182(14.1)$ & $322(17.4)$ \\
\hline$p$-value & 0.154 & $<0.05$ & $<0.05$ & 0.081 & $<0.05$ \\
\hline \multicolumn{6}{|l|}{ Region } \\
\hline Far western & $1(2.2)$ & $2(7.3)$ & $8(7.6)$ & $18(6.3)$ & $23(5.5)$ \\
\hline Eastern & $10(17.6)$ & $4(8.4)$ & $21(13.4)$ & $61(16.1)$ & $105(19.1)$ \\
\hline Central & $14(8.2)$ & $13(15.1)$ & $40(17.9)$ & 15 (16.7) & 96 (19.4) \\
\hline Western & $5(9.2)$ & $0(0)$ & 30 (18.3) & $43(9.5)$ & $110(20.2)$ \\
\hline Mid-western & $4(11.1)$ & $0(0)$ & $12(11.1)$ & $27(7.5)$ & $32(5.8)$ \\
\hline$p$-value & $<0.05$ & $<0.01$ & 0.204 & $<0.001$ & $<0.001$ \\
\hline
\end{tabular}

$P$ value obtained from chi square or Fisher's exact test analysis

age, and woman who delivered larger than average-sized infants were more likely to have CS delivery, although the latter two categories might be associated with medical indications [36] which was not analyzed in this study. This study identified that there is a high disparity in the utilization of cesarean section facilities across different developmental regions of Nepal. A study showed that Far-western and Mid-western developmental regions are underprivileged with inadequate health care facilities and low GDP [37]. This might be responsible for the higher CS rate observed in this study among regions with more advanced maternal and child health care services compared to those residing in a far western development region. Based on these findings, shifting resources from over-utilized areas to the areas where it is needed may be indicated.

The current study also identified that there are certain changes in the strength of correlates of CS from 2006 to 2016. In mid-2000s, correlates like region, wealth index and place of delivery were not associated at all or had very weak association with the institutional-based CS. However, over time the association became stronger reflecting the increase in inequitable access in CS service care utilization among few sub-groups of the population. Certain sub-groups of the population had far higher CS rate with stronger association than others in recent survey waves compared to 2006. Additionally, there had been vast advancement in the health care services as evidenced by increase in number of health care facilities and successful implementation of various incentive programs of Nepal Government to promote the institutional delivery [20]. However, the fact that certain subgroups of the population remain underprivileged still remains the same. Hence, Nepal government should focus more on reducing these disparities in between the sub-groups so that everyone in need could utilize the CS services from either public or the private health care facilities.

Another key finding of this study is that majority of primigravid women had delivered through CS. This is also true for other regions of the world as there are several factors influencing the preferences of a woman to undergo CS which include fear of labor pain, having a previous CS or living in a middle-income country, and so on [14, 38, 39]. Furthermore, women who delivered larger than average-sized infants had a 2-fold risk of getting CS than those who delivered an average-sized infant. This might be associated with some absolute and relative medical indications of CS, as suggested by Mylonas et al. [36].

The current study also observed the changes in the health care service utilization by pregnant women over the period of time. The health care utilization shifted from mostly home deliveries in 1996 to institutional deliveries in 2016. Therefore, the rising CS rate might indicate the progress in the development of maternal and child health care services of the country [34]. In contrast, the rapid increase of CS rate in the private organizations might be profit-driven or indicative of better implementation of safe motherhood and SBA training programs. 
Table 4 Bivariable and multivariable logistic regression analysis for the association between institutional cesarean section and selected covariates in survey waves 2006, 2011 and 2016

\begin{tabular}{|c|c|c|c|c|c|c|}
\hline & \multicolumn{2}{|l|}{2006} & \multicolumn{2}{|l|}{2011} & \multicolumn{2}{|l|}{2016} \\
\hline & cOR (Cl) & aOR (Cl) & COR (CI) & aOR (Cl) & cOR (Cl) & aOR (Cl) \\
\hline \multicolumn{7}{|c|}{ Region (Ref: Far-western) } \\
\hline Eastern & $1.88(0.85-4.19)$ & $1.31(0.57-3.03)$ & $2.84(1.41-5.73) * *$ & $1.99(0.93-4.25)$ & $4.04(2.35-6.95) * * *$ & $3.03(1.77-5.19) * * *$ \\
\hline Central & $2.67(1.42-5.00) * *$ & $1.54(0.78-3.02)$ & $2.98(1.53-5.78) * *$ & $2.15(1.05-4.40) *$ & $4.14(2.40-7.13) * * *$ & $2.58(1.52-4.40) * *$ \\
\hline Western & $2.73(1.35-5.51) * *$ & $1.91(0.91-4.00)$ & $1.56(0.76-3.18)$ & $1.38(0.65-2.90)$ & $4.34(2.57-7.35))^{* * *}$ & $2.91(1.69-4.99))^{* * *}$ \\
\hline Mid-western & $1.52(0.82-2.81)$ & $1.26(0.58-2.73)$ & $1.21(0.54-2.67)$ & $1.19(0.54-2.64)$ & $1.05(0.53-2.07)$ & $1.07(0.54-2.12)$ \\
\hline \multicolumn{7}{|c|}{ Age at first birth (Ref: $\leq 19$ ) } \\
\hline $20-29$ & $1.82(1.12-2.93) *$ & $1.71(1.01-2.90) *$ & $1.95(1.36-2.81) * * *$ & $1.62(1.08-2.43) *$ & $2.12(1.58-2.84) * * *$ & $1.49(1.09-2.02) *$ \\
\hline $30+$ & $6.04(1.94-18.8) * *$ & $4.60(1.70-12.43) * *$ & $5.85(2.18-15.6) * * *$ & $4.99(1.62-15.38) * *$ & $6.89(3.36-14.13) * * *$ & $4.85(2.27-10.39) * * *$ \\
\hline \multicolumn{7}{|c|}{ Birth order (Ref: Second +) } \\
\hline First & $2.26(1.26-4.07) * *$ & $2.01(1.10-3.68) *$ & $1.15(0.84-1.58)$ & $0.99(0.69-1.43)$ & $1.40(1.05-1.86) *$ & $1.21(0.88-1.67)$ \\
\hline \multicolumn{7}{|c|}{ Child size (Ref: Average) } \\
\hline Large & $2.28(1.12-4.64) *$ & $2.49(1.41-4.39) * *$ & $1.46(0.90-2.35)$ & $1.59(0.95-2.67)$ & $1.54(1.14-2.08) * *$ & $1.62(1.22-2.14) * *$ \\
\hline Small & $1.75(0.96-3.21)$ & $2.05(1.02-4.12) *$ & $1.11(0.59-2.06)$ & $1.17(0.62-2.20)$ & $1.15(0.83-1.58)$ & $1.36(0.97-1.90)$ \\
\hline \multicolumn{7}{|c|}{ ANC visit (Ref: 3 or less) } \\
\hline 4 and above & $1.88(1.07-3.31) *$ & $1.40(0.71-2.75)$ & $1.55(0.94-2.55)$ & $1.35(0.75-2.45)$ & $1.54(1.03-2.28) *$ & $1.28(0.87-1.87)$ \\
\hline \multicolumn{7}{|c|}{ Occupation (Ref: Not working) } \\
\hline Working & $0.39(0.24-0.62) * * *$ & $0.50(0.29-0.88) *$ & $0.60(0.43-0.83) * *$ & $0.81(0.57-1.17)$ & $0.78(0.60-1.01)$ & $1.11(0.83-1.49)$ \\
\hline \multicolumn{7}{|c|}{ Wealth index (Ref: Poorest) } \\
\hline Poorer & $0.66(0.24-1.79)$ & $0.65(0.24-1.77)$ & $0.29(0.08-0.99) *$ & $0.28(0.09-0.91) *$ & $1.28(0.69-2.36)$ & $0.95(0.51-1.80)$ \\
\hline Middle & $0.86(0.30-2.43)$ & $0.70(0.24-2.09)$ & $1.56(0.61-3.97)$ & $1.24(0.50-3.07)$ & $1.80(0.98-3.31)$ & $1.28(0.69-2.36)$ \\
\hline Richer & $0.93(0.36-2.37)$ & $0.68(0.24-1.91)$ & $1.49(0.59-3.74)$ & $0.90(0.33-2.43)$ & $2.04(1.21-3.45) * *$ & $1.33(0.77-2.28)$ \\
\hline Richest & $2.48(1.17-5.29) *$ & $1.77(0.66-4.79)$ & $2.23(0.90-5.53)$ & $0.98(0.35-2.78)$ & $6.01(3.57-10.11) * * *$ & $3.85(2.12-6.98) * * *$ \\
\hline \multicolumn{7}{|c|}{ Education (Ref: No education) } \\
\hline Primary or less & $1.21(0.66-2.23)$ & $0.92(0.47-1.80)$ & $1.59(0.85-2.97)$ & $1.56(0.80-3.06)$ & $0.93(0.59-1.47)$ & $0.88(0.54-1.44)$ \\
\hline Secondary + & $1.24(0.62-2.46)$ & $0.61(0.33-1.10)$ & $1.77(1.06-2.96) *$ & $1.31(0.66-2.57)$ & $1.73(1.18-2.53) * *$ & $0.94(0.60-1.47)$ \\
\hline \multicolumn{7}{|c|}{ Residence (Ref: Rural) } \\
\hline Urban & $1.44(0.87-2.38)$ & $1.10(0.63-1.90)$ & $2.31(1.63-3.26) * * *$ & $1.95(1.34-2.83) * * *$ & $1.36(1.01-1.85) *$ & $0.83(0.61-1.14)$ \\
\hline \multicolumn{7}{|c|}{ Place of delivery (Ref: Government sector) } \\
\hline Private sector & $1.00(0.55-1.81)$ & $1.33(0.78-2.26)$ & $2.63(1.87-3.70) * * *$ & $2.37(1.63-3.44) * * *$ & $2.42(1.76-3.32){ }^{* * *}$ & $2.22(1.62-3.03) * * *$ \\
\hline
\end{tabular}

Additional studies might shed more light on the accurate reasons for this increase in private organizations.

This study had several strengths. This is the first study showing the trend of institutional-based CS over a period of two decades in Nepal with the most recent data available. Also, the study used five waves of NDHS datasets, which includes a nationally representative sample population of Nepal. Therefore, our results are highly generalizable to the Nepalese population. Although there are few studies that showed the association between maternal sociodemographic characteristics and the CS rates, those were based on smaller sample size and non-representative populations [27]. In contrast, the current study focused on natal, antenatal factors and health care utilization variables, in addition to socio-demographics that might influence the rate of CS in the country. This study also reflected the existing disparities within various developmental regions of Nepal which might be useful to policymakers.

This study also had several limitations. Very low CS rates observed in 1996 and 2001 did not allow us to examine the correlates of CS for those years. Also, the NDHS data of Nepal did not have information about the type of cesarean section (emergency or elective), previous history of CS and medical indications of CS, which 
Table 5 Multivariable logistic regression analysis for the association between institutional cesarean section and selected covariates stratified by place of delivery in survey waves 2006, 2011 and 2016

\begin{tabular}{|c|c|c|c|c|c|c|}
\hline & Public, OR (Cl) & 2006 & Public, OR (Cl) & 2011 & Public, OR (Cl) & 2016 \\
\hline & & Private, OR (CI) & & Private, OR (CI) & & Private, OR (Cl) \\
\hline Region (Ref: 5) & & & & & & \\
\hline Eastern & $1.55(0.32-7.53)$ & $0.57(0.14-2.37)$ & $1.43(0.54-3.82)$ & $5.08(1.06-24.34) *$ & $2.05(1.13-3.73) *$ & $54.44(5.67-522.4) * *$ \\
\hline Central & $1.64(0.36-7.41$ & $1.09(0.43-2.76)$ & $1.28(0.54-3.01)$ & $6.83(1.42-32.81) *$ & $1.67(0.92-3.03)$ & $52.22(5.33-511.9) * *$ \\
\hline Western & $2.16(0.43-10.77)$ & $1.12(0.40-3.14)$ & $1.04(0.45-2.43)$ & $2.78(0.55-13.92)$ & $2.67(1.51-4.72) * *$ & $30.35(3.11-296.0) * *$ \\
\hline Mid-western & $0.50(0.10-2.58)$ & $2.97(1.17-7.49) *$ & $0.84(0.32-2.18)$ & $2.86(0.59-13.87)$ & $1.00(0.49-2.00)$ & $3.04(0.20-45.2)$ \\
\hline Age at first birth & (Ref: $\leq 19)$ & & & & & \\
\hline $20-29$ & $1.74(0.97-3.12)$ & $2.13(1.12-4.05) *$ & $1.61(0.90-2.88)$ & $1.49(0.78-2.83)$ & $1.42(0.99-2.05)$ & $1.55(0.84-2.89)$ \\
\hline $30+$ & $4.11(1.42-11.93) *$ & $32.48(2.70-391.1)^{* *}$ & $4.86(0.82-28.91)$ & $6.64(1.28-34.36) *$ & $4.48(1.88-10.65)^{* *}$ & $11.96(0.38-42.3)^{* * *}$ \\
\hline Birth order (Ref: & second + ) & & & & & \\
\hline First & $2.30(1.03-5.13) *$ & $1.34(0.61-2.93)$ & $0.70(0.42-1.17)$ & $1.65(0.96-2.86)$ & $1.17(0.82-1.69)$ & $1.27(0.75-2.2)$ \\
\hline Child size (Ref: A & (erage) & & & & & \\
\hline Large & $2.78(1.36-5.67) * *$ & $2.53(1.18-5.43) *$ & $1.07(0.57-1.99)$ & $2.76(1.28-5.97) * *$ & $1.52(1.03-2.22) *$ & $2.06(1.10-3.83) *$ \\
\hline Small & $1.88(0.74-4.77)$ & $2.24(0.70-7.15)$ & $0.58(0.23-1.46)$ & $2.70(1.16-6.27) *$ & $1.52(0.99-2.32)$ & $1.17(0.63-2.18)$ \\
\hline ANC visit (Ref: 3 & or less) & & & & & \\
\hline 4 and above & $1.22(0.56-2.67)$ & $1.44(0.65-3.20)$ & $1.18(0.63-2.19)$ & $1.76(0.59-5.29)$ & $1.15(0.63-2.09)$ & $1.46(0.80-2.67)$ \\
\hline Occupation (Ref: & Not working) & & & & & \\
\hline Working & $0.47(0.24-0.91) *$ & $0.47(0.21-1.08)$ & $0.87(0.50-1.51)$ & $0.73(0.40-1.34)$ & $0.93(0.66-1.32)$ & $1.58(0.99-2.51)$ \\
\hline Wealth index $(\mathrm{Re}$ & f: Poorest) & & & & & \\
\hline Poorer & $0.41(0.12-1.34)$ & $0.70(0.14-3.35)$ & $0.22(0.05-0.96) *$ & $0.48(0.10-2.27)$ & $1.21(0.59-2.48)$ & $0.45(0.13-1.58)$ \\
\hline Middle & $0.32(0.09-1.16)$ & $1.06(0.11-10.21)$ & $0.92(0.27-3.09)$ & $1.68(0.43-6.46)$ & $1.28(0.65-2.52)$ & $0.94(0.31-2.84)$ \\
\hline Richer & $0.75(0.28-1.99)$ & $0.09(0.02-0.36) * *$ & $0.68(0.21-2.20)$ & $1.14(0.29-4.49)$ & $1.54(0.77-3.08)$ & $0.84(0.31-2.23)$ \\
\hline Richest & $1.03(0.33-3.23)$ & $1.63(0.45-5.88)$ & $1.00(0.27-3.74)$ & $0.97(0.24-3.83)$ & $3.91(1.90-8.09) * * *$ & $2.82(1.05-7.56) *$ \\
\hline Education (Ref: $\wedge$ & o education) & & & & & \\
\hline Primary or less & $0.59(0.29-1.17)$ & $3.95(0.63-24.68)$ & $1.64(0.66-4.08)$ & $1.45(0.52-4.03)$ & $1.29(0.62-2.67)$ & $0.50(0.26-0.94) *$ \\
\hline Secondary + & $0.43(0.26-0.73) * *$ & $2.22(0.32-15.35)$ & $1.32(0.49-3.54)$ & $1.33(0.52-3.40)$ & $1.13(0.59-2.17)$ & $0.82(0.43-1.56)$ \\
\hline Residence (Ref: $\mathrm{F}$ & ural) & & & & & \\
\hline Urban & $0.93(0.49-1.74)$ & $1.35(0.67-2.72)$ & $0.56(0.34-0.92)^{*}$ & $0.43(0.23-0.79)^{* *}$ & $1.14(0.77-1.68)$ & $1.28(0.77-2.14)$ \\
\hline
\end{tabular}

Number of cases included in the multivariable model $N=5011$ (10 women did not report on ANC visits)

$O R$ adjusted odds ratio (adjusted for all covariates under analysis for each survey round)

Cl $95 \%$ confidence interval

${ }^{*}=P<0.05,{ }^{* *}=P<0.01,{ }^{* * *}=P<0.001$

could have allowed us to examine the causes of CS and whether the CS performed was medically appropriate. A more robust analysis of the appropriateness of CS could have been done using the Robson score. However, due to the lack of data on these variables, this study was not able to conclude whether the CS was clinically indicated or not. Despite the limitations, the study provided important evidence with regard to the increase in CS rate and socio-demographics as well as service utilization correlates of CS in Nepal.

\section{Conclusion}

This study, based on five waves of populationrepresentative data, showed that the CS rate had increased substantially during the last few decades which represents a success story of Nepal in meeting the MDG goal, as well as UHC agenda of reducing maternal mortality and morbidity by enabling greater access to emergency obstetric care services like CS. This upward trend was fueled by procedures performed at private institutions where this rate experienced nearly 3 -fold increase during 1996-2016. On the other hand, an almost unchanged CS rate in government institutes during this period suggests that there might be a persisting need for strengthening the comprehensive obstetric care services in the public sectors. However, a reasonable number of CS being performed in private organizations might be suggesting a commensurate rise in the number of 
women accessing private providers because of the incorporation of safe motherhood programs and incentive schemes of the Nepal government to encourage institutional deliveries into the private sectors as well. Considerable disparity in CS rates by developmental regions implicates that, inadequate number of medical institutions, along with a lack of maternal and health care facilities, are still widely prevalent in some regions. Hence, it is critical time for the Nepal government to develop policies which could help balance these prevailing disparities in the utilization of cesarean section procedure so that all Nepalese women can have equal access to maternal and child health care services.

\section{Supplementary Information}

The online version contains supplementary material available at https://doi. org/10.1186/s12884-020-03453-2.

Additional file 1. Proportion of institutional based cesarean section and its association with selected covariates and Multivariable logistic regression for the association between institutional cesarean section and measured characteristics by the survey year.

\section{Abbreviations}

CS: Cesarean section; MDG: Millennium Development Goals; SBA: Skilled Birth Attendants; NDHS: National demographic and health survey; $\mathrm{MCH}$ : Maternal and child health; USAID: United States Agency for International

Development; WHO: World health organization; BMI: Body mass index; ANC: Antenatal care; GDP: Gross Domestic Product; aOR: Adjusted odds ratio; OR: Odds ratio; COR: Crude odds ratio; Cl: Confidence interval; NPR: Nepalese Rupee; BEmOC: Basic emergency obstetric care; CEmOC: Comprehensive emergency obstetric care

\section{Acknowledgements}

The authors are truly grateful to St. Luke's International University, Tokyo Japan for providing an opportunity and guidance in conducting this study and also would like to extend their gratitude towards all the individuals involved in the data collection and management process for the DHS program. Moreover, our much appreciation to Professor Kevin Urayama from St. Luke's International University, for his contribution in performing English proofreading of this manuscript. Our warm appreciation to Non-Resident Nepalese Association (NRNA) for providing us with the opportunity to present the abstract of this paper at NRNA Second Global Nepali Health Conference held on September 18th - 20th. A deep appreciation to all the well-wishers. The statements made herein are solely the responsibility of the author.

\section{Authors' contributions}

Conceptualization AB, MR; Methodology AB, BD, MR; Validation AB; Formal analysis $A B$; Investigation $A B$; Resources $A B$; Data curation $A B, B D, M R$; Writing - original draft preparation $A B$; Writing - review and editing $A B, B D, M R$; Visualization $A B$; Supervision MR; Project administration AB. All authors have read and approved the final manuscript.

\section{Funding}

The authors received no specific funding for this research.

\section{Availability of data and materials}

The National Demographic and Health Survey data of Nepal can be obtained from the USAID's official website [28].

\section{Ethics approval and consent to participate}

This study analyzed data extracted from the NDHS 1996, 2001, 2006, 2011 and 2016 surveys. The ethical clearance for these surveys was obtained from Nepal Research Council and ICF Macro Institutional Review Board in
Calverton, Maryland, USA. The DHS data are publicly accessible, and we obtained the permission to use it in May 2019 after DHS reviewed our proposal and we accepted the terms and conditions attached with data sharing policy [28].

\section{Consent for publication}

Not applicable.

\section{Competing interests}

The authors declare no competing interests.

Received: 6 March 2020 Accepted: 24 November 2020

Published online: 09 December 2020

\section{References}

1. Althabe F, Sosa C, Belizán JM, Gibbons L, Jacquerioz F, Bergel E. Cesarean section rates and maternal and neonatal mortality in low-, medium-, and high-income countries: an ecological study. Birth. 2006;33:270-7. https://doi. org/10.1111/j.1523-536X.2006.00118.x.

2. Kim AM, Park JH, Kang S, Yoon TH, Kim Y. An ecological study of geographic variation and factors associated with cesarean section rates in South Korea. BMC Pregnancy Child. 2019;19(1):162 Available from: https:// www.ncbi.nlm.nih.gov/pubmed/31072318.

3. Gibbons Luz \& Belizán, José \& Lauer, Jeremy \& Betrán, Ana \& Merialdi, Mario \& Althabe, Fernando. The Global Numbers and Costs of Additionally Needed and Unnecessary Caesarean Sections Performed per Year: Overuse as a Barrier to Universal Coverage HEALTH SYSTEMS FINANCING. World Health Report 2010. 2010. p. 30.

4. Betran AP, Torloni MR, Zhang JJ, Gülmezoglu AM; WHO Working Group on Caesarean Section. WHO statement on caesarean section rates. BJOG. 2016; 123(5):667-70. https://doi.org/10.1111/1471-0528.13526. Epub 2015 Jul 22. PMID: 26681211; PMCID: PMC5034743.

5. Molina G, Weiser T, Lipsitz S, Esquivel M, Uribe-Leitz T, Azad T, et al. Relationship Between Cesarean Delivery Rate and Maternal and Neonatal Mortality. JAMA. 2015;314(21).

6. Adewuyi EO, Auta A, Khanal V, Tapshak SJ, Zhao Y. Cesarean delivery in Nigeria: prevalence and associated factors-a population-based crosssectional study. BMJ Open. 2019;9(6):e027273 Available from: https://www. ncbi.nlm.nih.gov/pubmed/31213450.

7. Maroufizadeh S, Amini P, Hosseini M, Almasi-Hashiani A, Mohammadi M, Navid B, et al. Determinants of Cesarean Section among Primiparas: A Comparison of Classification Methods. Iran J Public Health. 2018:47(12): 1913-22 Available from: https://www.ncbi.nlm.nih.gov/pubmed/30788307.

8. Lumbiganon P, Laopaiboon M, Gülmezoglu AM, Souza JP, Taneepanichskul S, Ruyan P, et al. Method of Delivery and Pregnancy Outcomes in Asia: The WHO Global Survey on Maternal and Perinatal Health 2007-2008. Obstet Anesth Dig. 2011;31(2):92-3 Available from: http://ovidsp.ovid.com/ovidweb. cgi $T=J S \& N E W S=n \& C S C=Y \& P A G E=$ fulltext $\& D=0 v f t \& A N=00132582-201106$ 000-00027.

9. Katikireddi SV, Gorman DR, Leyland AH. A comparison of trends in caesarean section rates in former communist (transition) countries and other European countries. Eur J Public Health. 2013;23(3):381-3 Available from: https://www.ncbi.nlm.nih.gov/pubmed/23204216.

10. Shahabuddin ASM, Delvaux T, Utz B, Bardají A, De BV. Determinants and trends in health facility-based deliveries and caesarean sections among married adolescent girls in Bangladesh. BMJ Open. 2016;6(9):e012424 Available from: https://doi.org/10.1136/bmjopen-2016-012424.

11. Mia MN, Islam MZ, Chowdhury MR, Razzaque A, Chin B, Rahman MS. Sociodemographic, health and institutional determinants of caesarean section among the poorest segment of the urban population: Evidence from selected slums in Dhaka, Bangladesh. SSM Popul Heal. 2019;8:100415 Available from: https://www.sciencedirect.com/science/article/pii/\$235282 7318301551.

12. Li H-T, Luo S, Trasande L, Hellerstein S, Kang C, Li J-X, et al. Geographic Variations and temporal trends in Cesarean delivery rates in China, 20082014. JAMA. 2017;317(1):69-76 Available from: https://doi.org/10.1001/jama. 2016.18663

13. Amini P, Mohammadi M, Omani-Samani R, Almasi-Hashiani A. Maroufizadeh S. Factors Associated with Cesarean Section in Tehran, Iran using Multilevel Logistic Regression Model. Osong Public Heal Res Perspect. 2018:9(2):86-92 Available from: https://www.ncbi.n/m.nih.gov/pubmed/29740533. 
14. Rahman MM, Haider MR, Moinuddin M, Rahman AE, Ahmed S, Khan MM. Determinants of caesarean section in Bangladesh: cross-sectional analysis of Bangladesh demographic and health survey 2014 data. PLoS One. 2018; 13(9):e0202879 Available from: https://www.ncbi.nlm.nih.gov/pubmed/302 08058.

15. Fesseha N, Getachew A, Hiluf M, Gebrehiwot $Y$, Bailey P. A national review of cesarean delivery in Ethiopia. Int J Gynecol Obstet. 2011;115(1):106-11 Available from: https://www.clinicalkey.es/playcontent/1-s2.0-S0020729211 003614

16. Jahnke JR, Houck KM, Bentley ME, Thompson AL. Rising rates of cesarean delivery in Ecuador: Socioeconomic and institutional determinants over two decades. Birth. 2019;46(2):335-43 Available from: https://onlinelibrary.wiley. com/doi/abs/10.1111/birt.12421.

17. Long Q, Kingdon C, Yang F, Renecle MD, Jahanfar S, Bohren MA, et al. Prevalence of and reasons for women's, family members', and health professionals' preferences for cesarean section in China: a mixed-methods systematic review. PLoS Med. 2018;15(10):e1002672.

18. Hoxha I, Fejza A, Aliu M, Jüni P, Goodman DC. Health system factors and caesarean sections in Kosovo: a cross-sectional study. BMJ Open. 2019:9(4): e026702 Available from: https://doi.org/10.1136/bmjopen-2018-026702.

19. Nilsen C, Østbye T, Daltveit AK, Mmbaga BT, Sandøy IF. Trends in and sociodemographic factors associated with caesarean section at a Tanzanian referral hospital, 2000 to 2013. Int J Equity Health. 2014;13(1):87 Available from: https://www.ncbi.nlm.nih.gov/pubmed/25319518.

20. Bhattarai A, Dharel D, Kumar N. The safe delivery incentive program in Nepal: towards women's empowerment. Int J Med Sci public Heal. 2016; 5(10):2108-13 Available from: https://www.bibliomed.org/mnsfulltext/67/6 7-1457002221.pdf?1602905273.

21. Devkota M, Shakya G, Pratap N, Dariang, K C M, Upadhyay, M. T, Karn S, et al. Readiness of Comprehensive Emergency Obstetric and Neonatal Care in Nepal, National Health Sector Support Program and Ministry of Health and Population of Nepal [Internet]. Kathmandu; 2011. Available from: http:// www.nhssp.org.np/NHSSP_Archives/ehcs/CEONC_readiness_december2011. pdf.

22. Rai SK, Rai G, Hirai K, Abe A, Ohno Y. The health system in Nepal - an introduction. Environ Health Prev Med. 2001;6(1):1-8.

23. Otolorin E, Gomez P, Currie S, Thapa K. Essential basic and emergency obstetric and newborn care: from education and training to service delivery and quality of care. Int J Gynecol Obstet. 2015;130:S46-53.

24. Neuman M, Alcock G, Azad K, Kuddus A, Osrin D, More N, et al. Prevalence and Determinants of Caesarean Section in Private and Public Health Facilities in Underserved South Asian Communities: Cross-Sectional Analysis of Data From Bangladesh, India and Nepal. BMJ Open. 2014;4(12).

25. Dhakal Rai S, Regmi PR, Teijlingen EV, Wood J, Dangal G, Dhakal KB. Rising Rates of Caesarean Section in Urban Nepal. J Nepal Health Res Counc. 2019; 16(41):479-80. PMID: 30739926.

26. Ministry of Health and Population of Nepal. Socioeconomic differentials in caesarean section rates in Nepal. 2020.

27. Prakash KC, Neupane S. Cesarean deliveries among Nepalese mothers: changes over time 2001-2011 and determinants. Arch Gynecol Obstet. 2014;289(2):421-7.

28. Ministry of Health and Population of Nepal D of HS. Annual Report 2074/75 (2017/18): Ministry of Health and population of Nepal D of HS; 2074. p. 86-9.

29. Ministry of Health and Population of Nepal D of HS. Annual Report 2074/75 (2017/18). 2074.

30. Niino $Y$. The increasing cesarean rate globally and what we can do about it. Biosci Trends. 2011;5(4):139-50 Available from: https://jlc.jst.go.jp/DN/JALC/ 00389767372 ?from=SUMMON.

31. Guilmoto CZ, Dumont A. Trends, Regional Variations, and Socioeconomic Disparities in Cesarean Births in India, 2010-2016. JAMA Netw Open. 2019; 2(3):e190526 Available from: https://www.ncbi.nlm.nih.gov/pubmed/30901 040 .

32. Geleto A, Chojenta C, Musa A, et al. Barriers to access and utilization of emergency obstetric care at health facilities in sub-Saharan Africa: a systematic review of literature. Syst Rev. 2018;7:183. https://doi.org/10.1186/ s13643-018-0842-2.

33. Jahn A, Dar lang M, Shah U, Diesfeld HJ. Maternity care in rural Nepal: a health service analysis. Trop Med Int Health. 2000;5:657-65. https://doi.org/ 10.1046/j.1365-3156.2000.00611.x.

34. Lama S, Krishna AK. Barriers in Utilization of Maternal Health Care Services: Perceptions of Rural Women in Eastern Nepal. Kathmandu University
Medical Journal (KUMJ). 2014;12(48):253-8. https://doi.org/10.3126/kumj. v12i4.13730.

35. Dankwah E, Kirychuk S, Zeng W, Feng C, Farag M. Socioeconomic inequalities in the use of caesarean section delivery in Ghana: a crosssectional study using nationally representative data. Int J Equity Health. 2019;18(1):162. https://doi.org/10.1186/s12939-019-1063-6. PMID: 31653255; PMCID: PMC6814993.

36. Mylonas I, Friese K. Indications for and Risks of Elective Cesarean Section. Dtsch Aerzteblatt Online. 2015:

37. Vandernoot J, Van Hove C. Disparities between Development Regions and District Development Committees in Nepal. Int Adv Econ Res. 2014;20:3534. https://doi.org/10.1007/s11294-014-9479-7.

38. Mazzoni A, Althabe F, Liu NH, Bonotti AM, Gibbons L, Sánchez AJ, et al. Women's preference for caesarean section: a systematic review and metaanalysis of observational studies. Bjog. 2011:118(4):391.

39. Lukasse M, Vangen S, Øian P, Schei B. Fear of childbirth, women's preference for cesarean section and childhood abuse: a longitudinal study. Acta Obstet Gynecol Scand. 2011;90(1):33-40. https://doi.org/10.1111/j.16000412.2010.01024.x. Epub 2010 Nov 26. PMID: 21275913.

\section{Publisher's Note}

Springer Nature remains neutral with regard to jurisdictional claims in published maps and institutional affiliations.

\section{Ready to submit your research? Choose BMC and benefit from:}

- fast, convenient online submission

- thorough peer review by experienced researchers in your field

- rapid publication on acceptance

- support for research data, including large and complex data types

- gold Open Access which fosters wider collaboration and increased citations

- maximum visibility for your research: over $100 \mathrm{M}$ website views per year

At BMC, research is always in progress.

Learn more biomedcentral.com/submissions 